This article was downloaded by:[Chambers, lain]

On: 31 May 2007

[Chambers, lain]

Access Details: [subscription number 779220872]

Publisher: Routledge

Informa Ltd Registered in England and Wales Registered Number: 1072954

Registered office: Mortimer House, 37-41 Mortimer Street, London W1T 3J H, UK

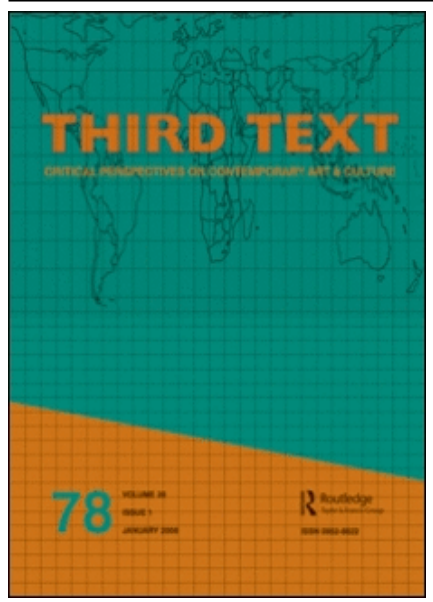

\title{
Third Text
}

Publication details, including instructions for authors and subscription information: http://www.informaworld.com/smpp/title content=t713448411

\section{Landscapes, Art, Parks and Cultural Change}

To cite this Article: Chambers, Iain, Calabritto, Claudio, Carmen, Monica, Esposito, Raffaele, Festa, Mario, Izzo, Rosita and Lanza, Orlando, 'Landscapes, Art, Parks and Cultural Change', Third Text, 21:3, $315-326$

To link to this article: DOI: $10.1080 / 09528820701362431$

URL: http://dx.doi.org/10.1080/09528820701362431

\section{PLEASE SCROLL DOWN FOR ARTICLE}

Full terms and conditions of use: http://www.informaworld.com/terms-and-conditions-of-access.pdf

This article maybe used for research, teaching and private study purposes. Any substantial or systematic reproduction, re-distribution, re-selling, loan or sub-licensing, systematic supply or distribution in any form to anyone is expressly forbidden.

The publisher does not give any warranty express or implied or make any representation that the contents will be complete or accurate or up to date. The accuracy of any instructions, formulae and drug doses should be independently verified with primary sources. The publisher shall not be liable for any loss, actions, claims, proceedings, demand or costs or damages whatsoever or howsoever caused arising directly or indirectly in connection with or arising out of the use of this material.

(c) Taylor and Francis 2007 


\title{
Landscapes, Art, Parks and Cultural Change
}

\author{
Iain Chambers, Claudio Calabritto, \\ Monica Carmen, Raffaele Esposito, \\ Mario Festa, Rosita Izzo and Orlando Lanza
}

\section{THE INSISTENCE OF LOCALITY}

It often seems that there is no longer a living landscape to consider but only an abstract territorial space, which occasionally acquires the status of a panorama, to analyse. Geography, as the inscription of the earth, has apparently lost touch with its 'origins' and is seemingly no longer able to narrate the landscape in a manner that renders it a significant social and human experience. The conjectural reading and planning of space perhaps needs to be rethought in a multidisciplinary perspective proposed by actors willing to participate in interpretations that locate in the historical formation of 'social capital' the impulse for transformation.

What might be considered 'spontaneous' architecture - from vernacular, rural buildings to Brazilian favelas - proposes a world within a world. Such spontaneity arises from the material expression, sometimes desperate, that gives form to a need, an urgency, that relays values and problematics that involve the lived limits and hopes of a community. It is this prospect that draws us into the specifics of a particular reality. Elsewhere, non-spontaneous interventions tend to mirror an individual will that ignores the development of collective sentiments and cancels the awareness of particular limits and needs. Translated into the immediacies of First World life, where one does not die of hunger and suffering, and where migrant visas are not required, this means to inhabit a world in which there is a continual dispersion of resources accompanied by the creation of objects that do not respond to needs. It is a world unable to elaborate scenarios evoking diverse possibilities; it is a world of global uncertainty sustained by fear and borders, a world that tends to dramatically implode upon itself:

In the metropolitan areas one witnesses a new elaboration of urban space with the birth of zones exclusively for the middle class, in the Arizona desert emerge new settlements, rigidly protected and surrounded by walls. 
Such 'gated communities' multiply in the south of the world (including China), just like the 'free zones' and the maquillas, territories in which union (even human) rights, together with ecological legislation, are suspended in order to permit the free circulation of profit and capital. ${ }^{1}$

Meanwhile, there is in Italy the ongoing privatisation of historical sites and parks, with the state selling off such areas for eventual exploitation by tourism without ever considering an eventual interaction with local concerns, thereby promoting the progressive impoverishment of resources. Then there is the phenomenon of 'spontaneous' appropriation of territory and the mushrooming of illegal building, widespread all along the coastlines of southern Italy.

The weakness of existing projects, irrespective of the presence of an architect or an artist even of notable value, is that the individualised expression of an intellectual or artistic discourse is unable to establish significant relationships with the everyday textures and habits that have emerged over the course of time in the locality, or to establish significant new relationships in situations in which inherited relationships are undergoing a crisis.

Working in order to re-create such relationships also means seeking to establish a new imaginary that commences from the materials at hand, from the activities and resources already circulating in the locality. From here it becomes possible to draw the existing situation towards a future based on objectives and values that are already perceived as a priority. This implies the promotion of positive examples, simultaneously accompanied by experimental projects that can open up and promote new perspectives. On the basis of such premises there emerges a necessity that is not exactly new, but which has until recently been relegated to minor importance in the institutional planning of resources and development. This is the necessity - precisely in the very moment that it is becoming clear that such a space and its accompanying resources are being dramatically reduced - of active participation in the construction of a quotidian living space where individuals are not simply relegated to the role of users and consumers.

The constitution of regional parks is part and parcel of this type of 'resistance' and its re-appropriation of space, even if it emerges in a context that is radically different from similar proposals realised in the urban territories of the metropolis. There is little that is initially 'spontaneous' in what is fundamentally an imposed structure elaborated through the establishing of borders and in decisions concerning what enters and what is excluded from the park. In the subsequent phase, however, the eventual success of the structure depends on the degree to which it manages to sustain projects and is able to develop the conscious participation of the park's population in realising and identifying with its potential and collective development.

1 Tonino Perna, Aspromonte, Bollati Boringhieri, Turin, 2002, p 82

\section{NATURE AND/OR LANDSCAPE: THE MATESE REGIONAL PARK}

Only eleven percent of the Earth's surface is covered by parks and protected areas. Perhaps here it becomes most urgent to propose a 
radical change in rethinking the concept of nature and with it the theme of the landscape:

$\ldots$ if they wish to survive their encirclement the parks must become an avant-garde, providing socio-ecological reference points, laboratories of a sustainable future. They must transform themselves into political subjects capable of constructing local projects with global value. ${ }^{2}$

After the 1972 Stockholm United Nations conference on the environment, a discussion was launched that led to the formulating of a basic distinction between 'nature reserves' (largely inspired by the North American model) and 'parks'. In 'nature reserves', the priority lies almost exclusively in conserving the natural habitat, while in 'parks' the principal objective is that of seeking to establish a reciprocal compatibility between the natural environment and social development. From Spain, with the exception of Catalonia, to central-southern Italy, from Portugal to as far as Greece, the parks tend to be localised in areas 'external' to major economic nodes, areas that can be considered 'marginal' to, or 'saved' from, industrialisation. National and regional parks emerge in areas that until recently would have been defined as 'backward' but which, with the institution of a park, now acquire another meaning. Frequently the park is perceived by the local administration as a hindrance, blocking the actions of local actors and interests. Only when the potential prospects of development are connected to a shared awareness that proposes the landscape as an 'economic resource' does it become possible to invert a purely instrumental understanding and arrive at a widespread appreciation of the value promoted by the park itself.

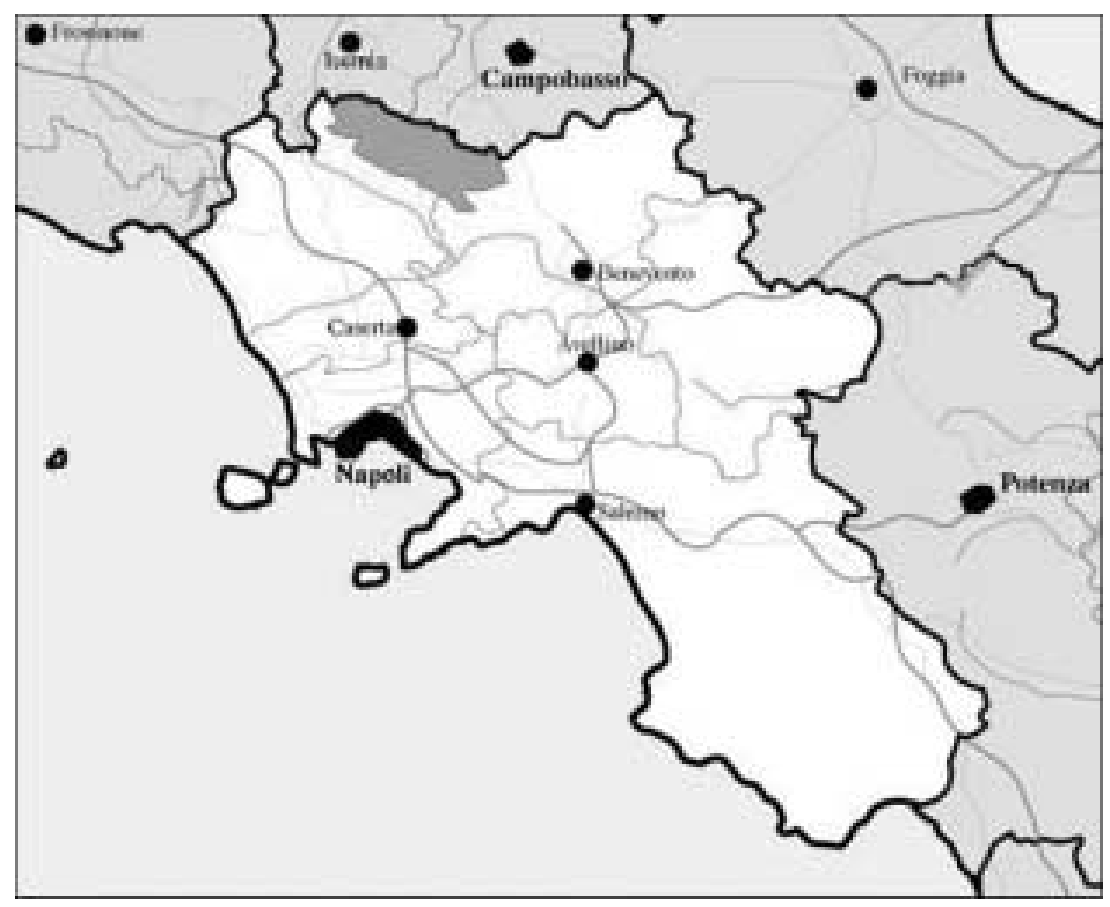


Matese is a mountain chain that lies between the regions of Campania and Molise. The Campania side comprises some 300 square kilometres of woods. A large proportion of the human settlement has experienced emigration since the 1950s; this, in turn, has led to a crisis in the local, traditional economy and the subsequent abandonment of the historical centres of the towns and villages. The Matese Regional Park was instituted in 1993 by the Campania Regional government, but only after a long and tortuous bureaucratic passage did it become a reality in April 2002. It involves an area of 250 square kilometres, including the lakes of Matese, Gallo and Letino, as well as numerous streams and rivers. In the park itself are twenty-two municipalities belonging to the provinces of Caserta and Benevento.

\section{paeSEsaggio AND LANDSCAPE WISDOM}

In the spirit of the guiding principles of the European Union-financed Integrated Territorial Projects, and following the proposals and parameters laid out in the original Document of Strategic Orientation of the Matese Regional Park, the research group paeSEaggio ('landscape wisdom' or 'wise settlement') has elaborated a programme inspired by the slogan 'From the Matese Park to the European Park'. This particular project involves diverse interventions in the five municipalities of Capriati al Volturno, Fontegreca, Letino, Gallo Matese and Prata Sannita. Through common agreement the municipalities have created a mutually supportive network to pool energies and resources.

In this context the paeSEsaggio group has elaborated three major axes of intervention: Urban Node, the Village of Art, and an eventual Centre for ecological education. Urban Node is a project elaborated in collaboration with the Centre of Postcolonial Studies at the Oriental University, Naples, along with the architects Monika Wisniewska and Aleksandar Cetković in Zurich, under the general direction of Iain Chambers. Conceived as a network of structures for the park, Urban Node is a

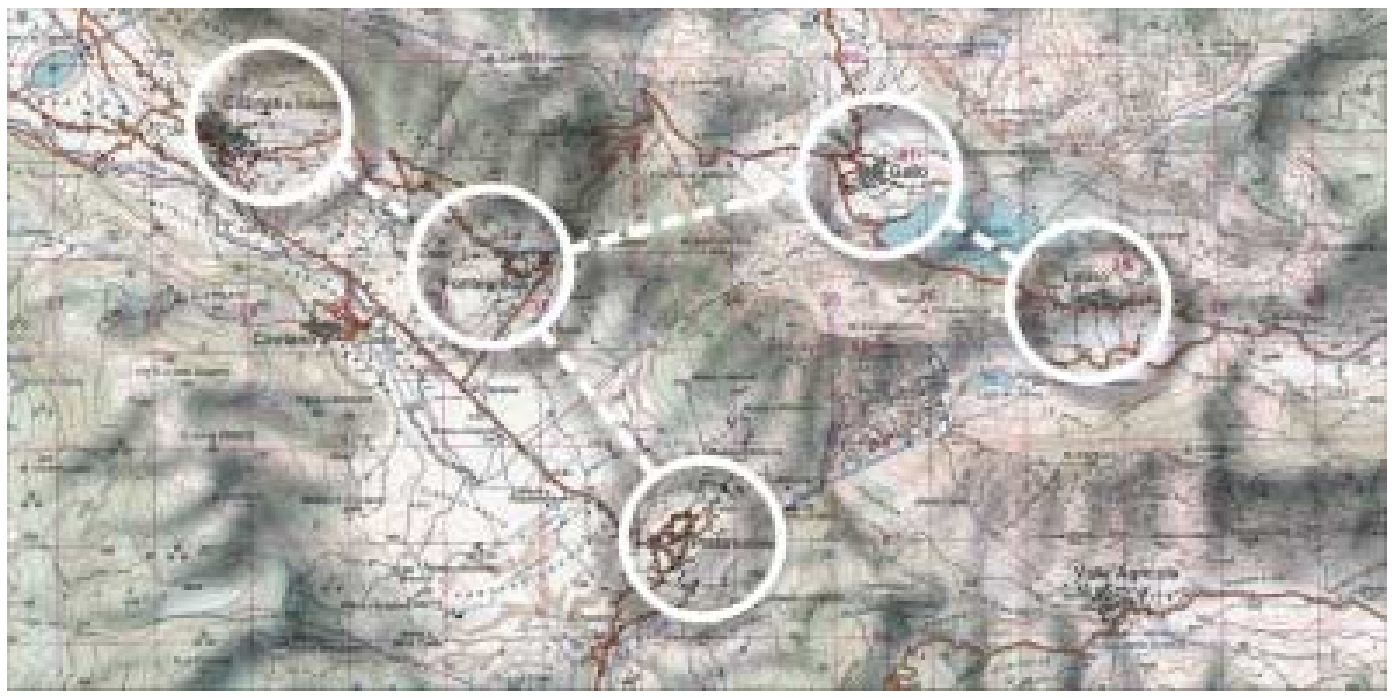


multidisciplinary and multimedia laboratory where the local communities actively participate in the elaboration of their history and, via international contacts and exchange, develop new modes of interpretation and intervention in their immediate locality. The initiative, which involves an intense programme of research along with a continual series of interventions in the area, seeks to promote an economic and cultural revitalisation of the Matese Regional Park. In this particular region, populations arriving from the north, south and east of Europe have settled. The spoken dialect and costumes worn on festive occasions still reveal the traces of such encounters, clashes and contaminations. Subsequently, in the last century there were major migrations out of the area to the Americas, northern Europe and Australia, with the consequent stretching of hopes and traditions into the everyday experiences of other worlds.

The artistic interventions in the park are coordinated in the 'Village of Art', an annual event that intersects with the research of Urban Node and the associated Laboratory of Memory. The manifestation involves the collective realisation of artworks in the five municipalities. The works are the result of a collective enterprise involving the local populations and artists invited from European and extra-European contexts. The idea is to create a moment of interactive activity that is both social and aesthetic, and where inherited perceptions of the locality can be challenged, interrogated and reinvented. The 'external' eye not only serves to create the bases for new interpretations but also to draw local concerns and perspectives into wider territories characterised by diverse understandings and skills.

This type of intervention transfers the focus from the product to the process, seeking in the modalities and qualities of the collective enterprise, rather than merely in the isolated artwork, the essential meaning of the overall operation. The articulation of such interventions via diverse moments - including the possibility for artists to undertake a preliminary survey of the localities and to reside in them, collective encounters with the villagers to decide on where and how to intervene, public presentations of the projects, subsequent emailing, networking and contact building - has as its focal point the formation of a critical action that is developed through the ongoing interaction between all the actors involved in the process.

Such an active construction of the event in loco by the cultural operators, artists and the inhabitants becomes a means whereby to understand and promote collective desires and individual aspirations which, in turn, are able to modify everyday experience and generate new and diverse modalities in the appropriation and management of space. The comprehension of desire, besides providing the motor for the construction of the event, is also primary in the ongoing elaboration of the collective imaginary of the territory. It is this imaginary that influences both the manner of exploiting and managing this space as well as the specific perception of the location and de-location of the site within an altogether more extensive geopolitical and economic context.

The intervention develops along two thematic axes between which the action of the project is suspended. On one hand, there is the theme of identification: the articulation of identity impulses within a collective perspective often composed of dramatic events (for example, the history of nineteenth-century anarchy and brigandage, the phenomenon of mass 
3 This is the full list of artists involved in the Village of Art in 2005 and 2006:

Laloba, Thomas Link, Feld 72, Bill Hackney, The Harrison Studio, Giuliano Mauri, Bruno Donzelli, Cristina Piza, Luigi Spina, Michele Iodice, Pasquale Musella, Giuliano Orsingher, Stalker/ Osservatorio Nomade, Malaguti e Montesarchi. migration) that have left their mark on the social, economic and individual realities of the region. How, in this space, will memory sew together the past and open up new scenarios on the future? Where and how will such memories be effected? The artistic interventions seek to raise and elaborate such questions in a communal context, producing a more fluid and problematic understanding of locality and belonging.

The other dimension is directed towards the landscape and the question of the relationship between a socialised humanity and the natural environment. Hence the artworks seek to respond to the context to which they have been consigned. Their particular location includes the comprehension of pre-existing natural coordinates (the lie of the land, the fauna, animal habitats) and anthropological systems (the human occupation and organisation of the locality) brought together in reciprocal valuation. This underlines the role that the processes of elaborating the artwork can have in critically researching relationships between 'nature' and 'culture' in a manner that is non-invasive and which transforms a narrowly pragmatic understanding into something that is altogether more complex, problematic and hence 'freer'. What is the actual imaginary that sustains such a relationship? How might it be re-created in order to be exposed to modification and transformation induced by the passage of sociology and ecology, historiography and zoology, ethics and aesthetics? It is with such questions in mind that the following collective artistic practices, which constitute part of the mobile constellation of the Village of Art in the last two years (not all of the works are presented here), has worked. ${ }^{3}$

feld 72 (Architects - Vienna: http://www.feld.72.at)

Project: Million Donkey Hotel (http://www.milliondonkeyhotel.net ) In the medieval town of Prata Sannita abandoned buildings are reproposed as the shared context of a virtual hotel. With the participation of the local inhabitants four of these 'lost' spaces were transformed into inhabitable installations. The Million Donkey Hotel is the beginning of the reactivation of some forgotten parts of the town and an expansion of its public space. It is now run by an association of local volunteers and can be booked at: http://www.milliondonkeyhotel.net

Cristina Piza (Photographer - San Francisco: http://www.cristinapiza.com)

Project: Icons of Memory

The streets and squares of Gallo Matese and Letino become the sites of interaction between residents and travellers, between those who remained and those who have departed. Old photographs discovered in forgotten trunks acquire a public dimension. The location of these icons of memory in strategic points of the two villages, usually in the vicinity of where the subjects once lived, becomes the focus of discussion and curiosity, leading to a three-dimensional 'mapping' of the locations that dilute the present and render the past slightly surreal but also pleasurable.

Stalker/Osservatorio Nomade (Architects, Artists - Rome: http:// www.osservatorionomade.net)

Project: Gallesi in the World 


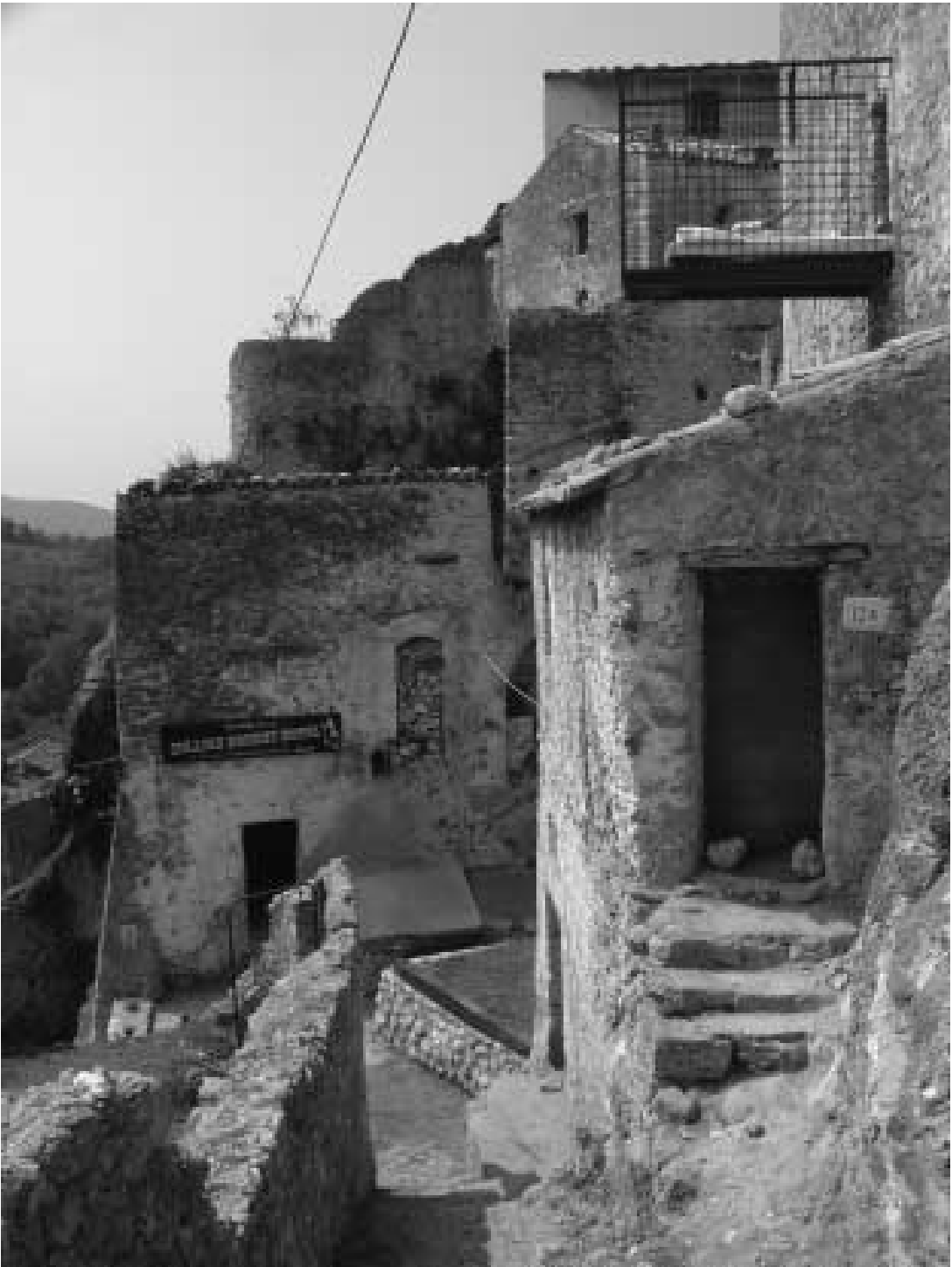

The houses and buildings of Gallo Matese provide the scenario for the installation of some 500 flags that signify the eventual destination of family members and friends. The diasporas of migration, lived by local inhabitants as a 'loss' that has profoundly weakened immediate human resources, provide the occasion to reconsider one's self, one's history and one's location as a 'centre of expansion' that opens up new channels for conceiving reality. The installation concluded with a public party entitled 'Gallesi in the World'.

Another installation - Urban Embroidery - was constructed in a zone of the village that is abandoned and in ruins. This event extended the physical space between the abandoned houses through the ancient art of lacework embroidery whereby the whole area was 'sewn' together with 
the intricate patterns created by the passage of string from building to building. This became an interesting metaphor for the collective stitching together of a network of memories, inserted in diverse histories and geographies, that proposes a diverse relationship with an external world that simultaneously circulates within.

Giuliano Mauri (Land artist - Milan: http://www.artesella.it )

Project: Migrant Rafts

The lake of Gallo remains in the local imaginary as the place that swallowed up the most fertile soil. When the lake was artificially created for a hydroelectric scheme, it forced many of the inhabitants to migrate. The cement wall of the dyke is the most evident sign of a process that has rendered the lake and its immediate surrounding off-limits. The poetical process unleashed by Mauri's work collates the inherited reality of this site, while simultaneously registering an awareness of new possibilities. Three floating structures of eighty, fifty and thirty square metres were suspended in the waters of the lake. Although anchored they have the possibility of drifting over the surface. These mobile islands, with their archetypal forms, collectively constructed in wood, metal and rope, 'live' on the water, promoting new reference points in the landscape.

Helen and Newton Harrison (Architects/Land artists - San Diego: http:// www.peninsula-europe.net)

Project: The Reign of the Path

Here, in the ecosystem around the lake of Gallo, the idea was to plant new forms of reciprocity. The rediscovery of this locality occurs through the creation of a footpath studded with small sites and installations flanking the lake and which serve physically to link the villages of Gallo Matese and Letino.

Thomas Link (Sculptor - Munich: http://www.thomas-link.com)

Project: Cypress

The participants in this laboratory became part of a 'living sculpture' that culminated in a performance in which nine cypress trees were planted, and in a space nominated as the 'mill of time' a giant stone brought down from the mountain was positioned. In this manner, a site was established between the cypress forest and the village of Fontegreca, providing a point of encounter where both narratives and experiences acquiring the form of performances, maps and videos are collated.

Laloba (Land artists - Naples)

Project: Fossil Branches

Entwined branches and sheets of metal provide the materials for the composition of a series of sculptured 'fossils' deposited in a large field on the banks of the lake at Capriati al Volturno. The evocative force of these signs, which delineate a passage from the centre of habitation towards the lake, culminates in 'the fish': a structure fifteen metres long and five metres high.

One of the aims of Urban Node is to reconfigure this cultural landscape through a new and diverse 'mapping' of passages of memory and history in a manner that reduces their progressive marginalisation. In the ambiguous and excluded static of the past, or what Paul Carter calls the 


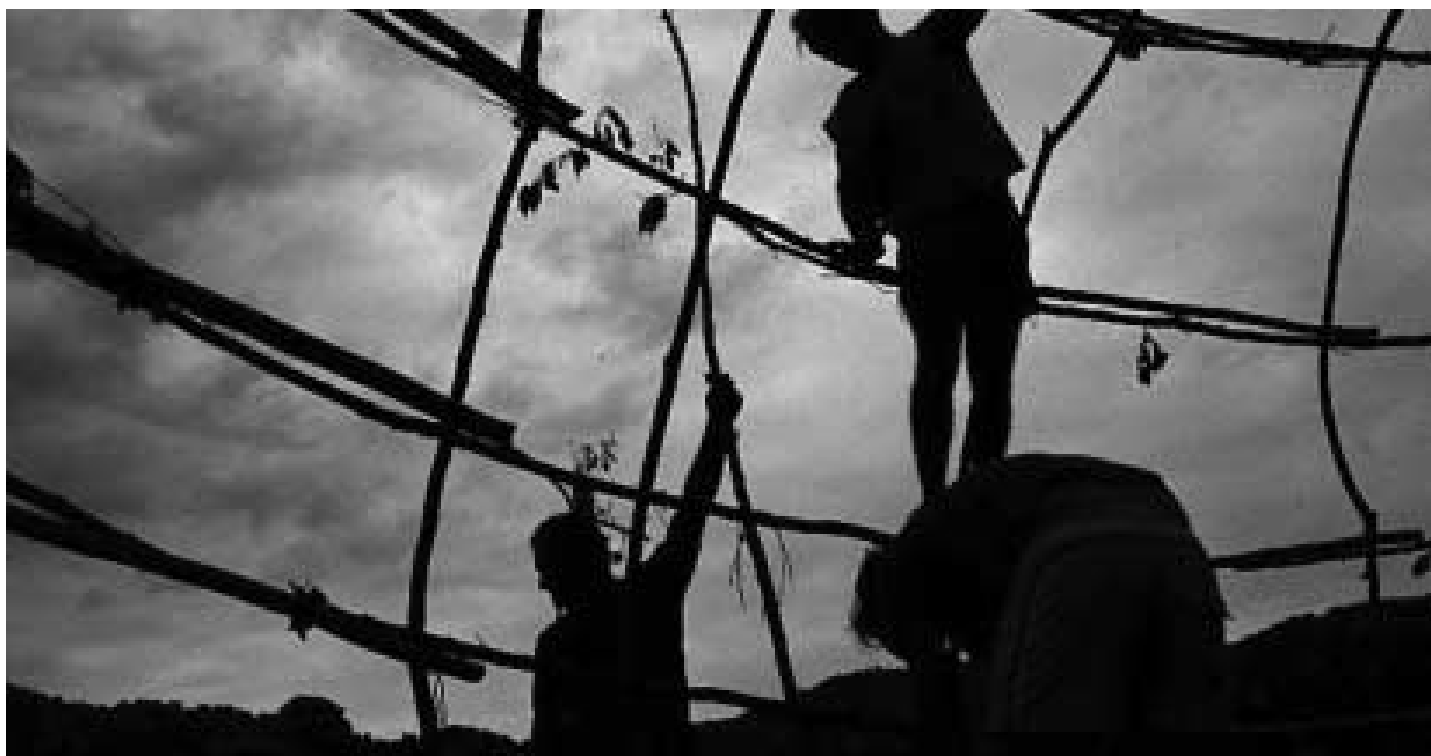

Giuliano Mauri

Art project. Falisca niarenta

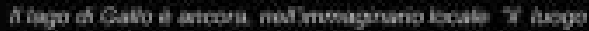

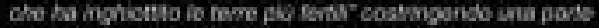
mpante dols peoscasare od enprave above

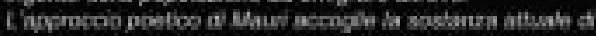

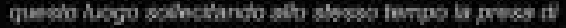

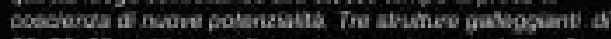

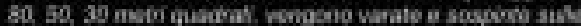

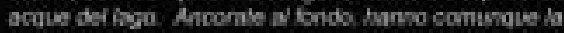

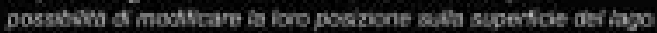

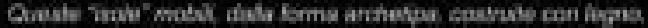

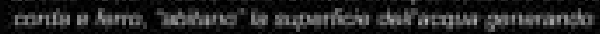

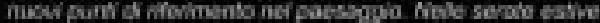

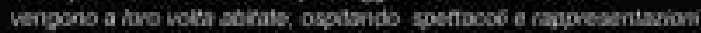

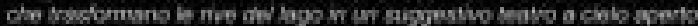

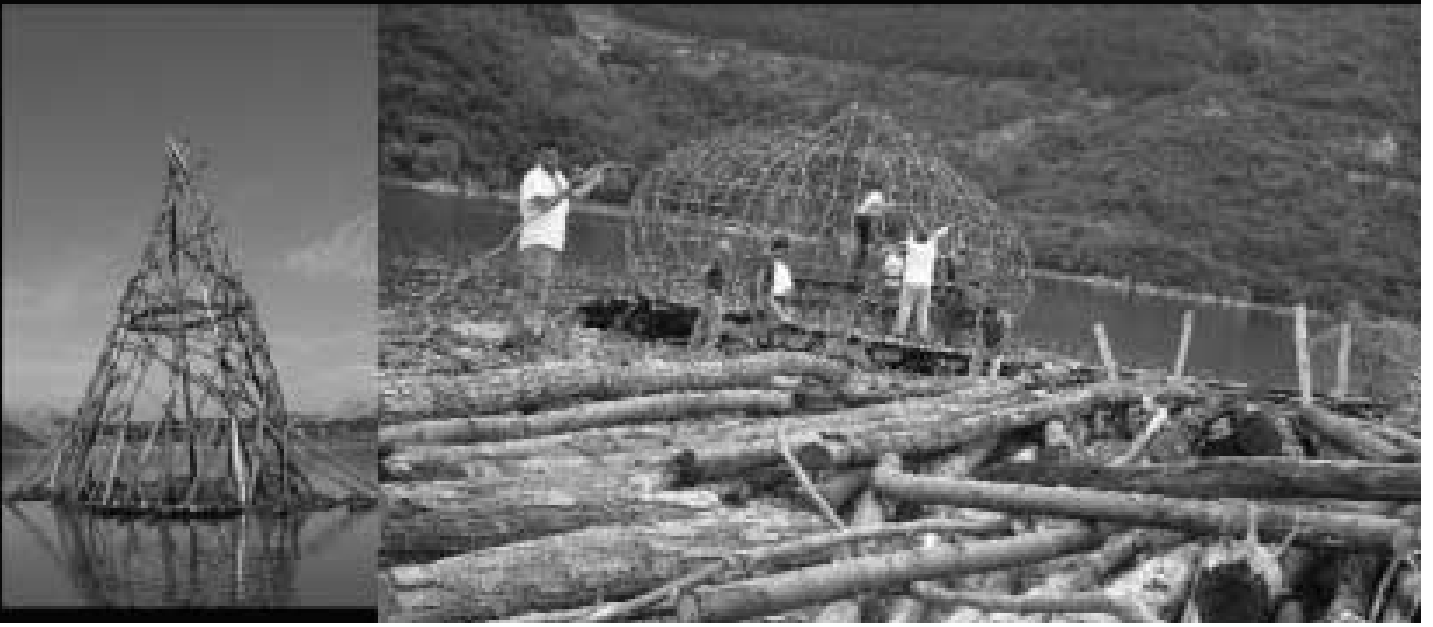


Thomas Link

Ant project. pregetle canssos

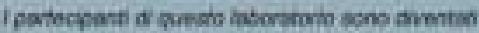

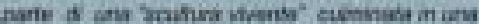

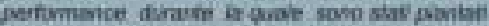

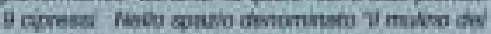
temso: o stats pesievonata uni aronce pietra. recuverata do ina cava atts montagna.

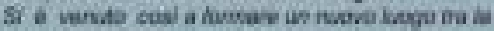

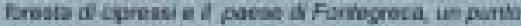

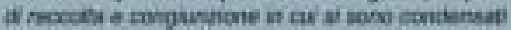

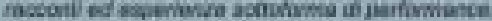
rappenus is vidoostorimentation

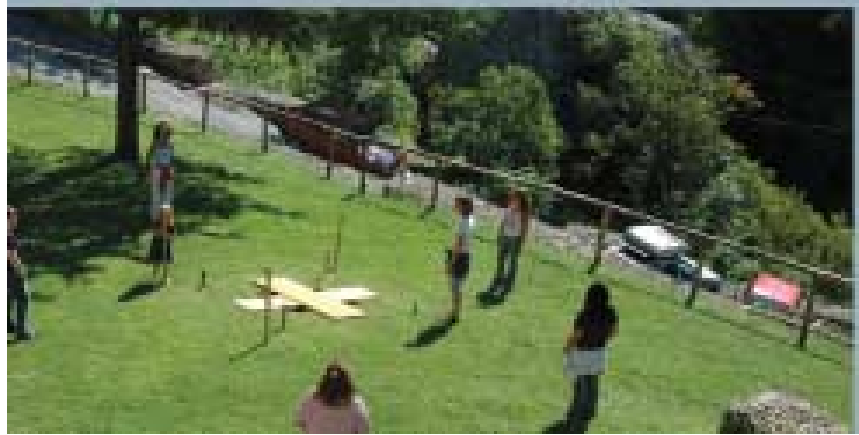

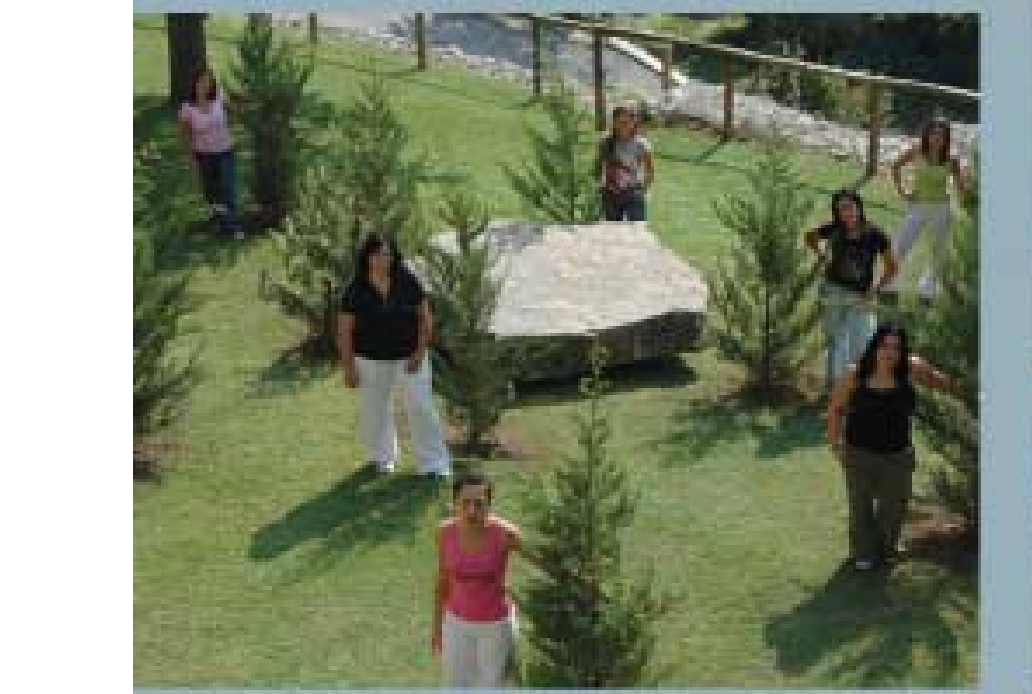
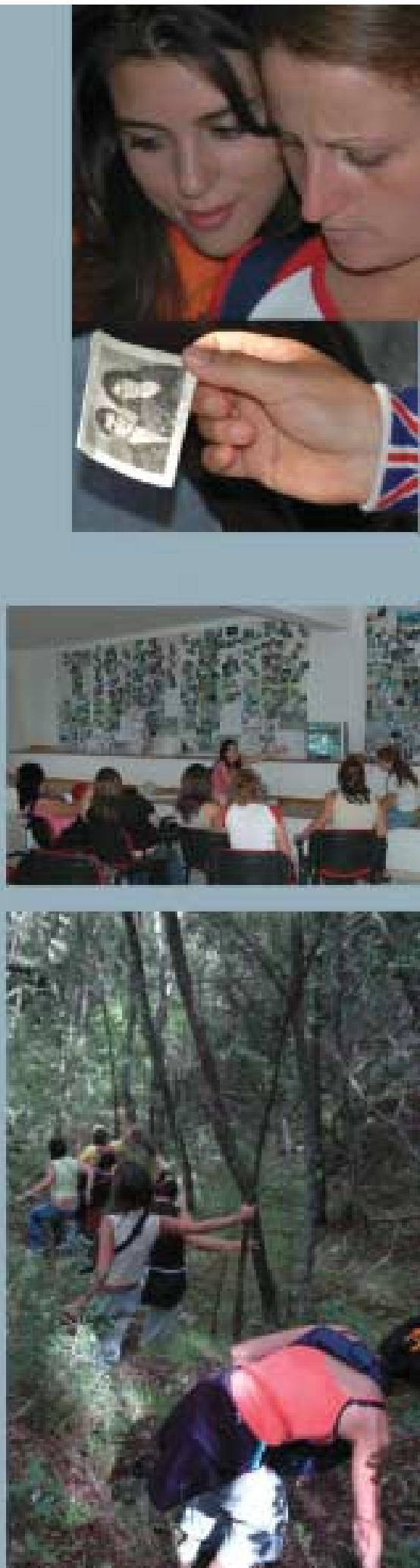


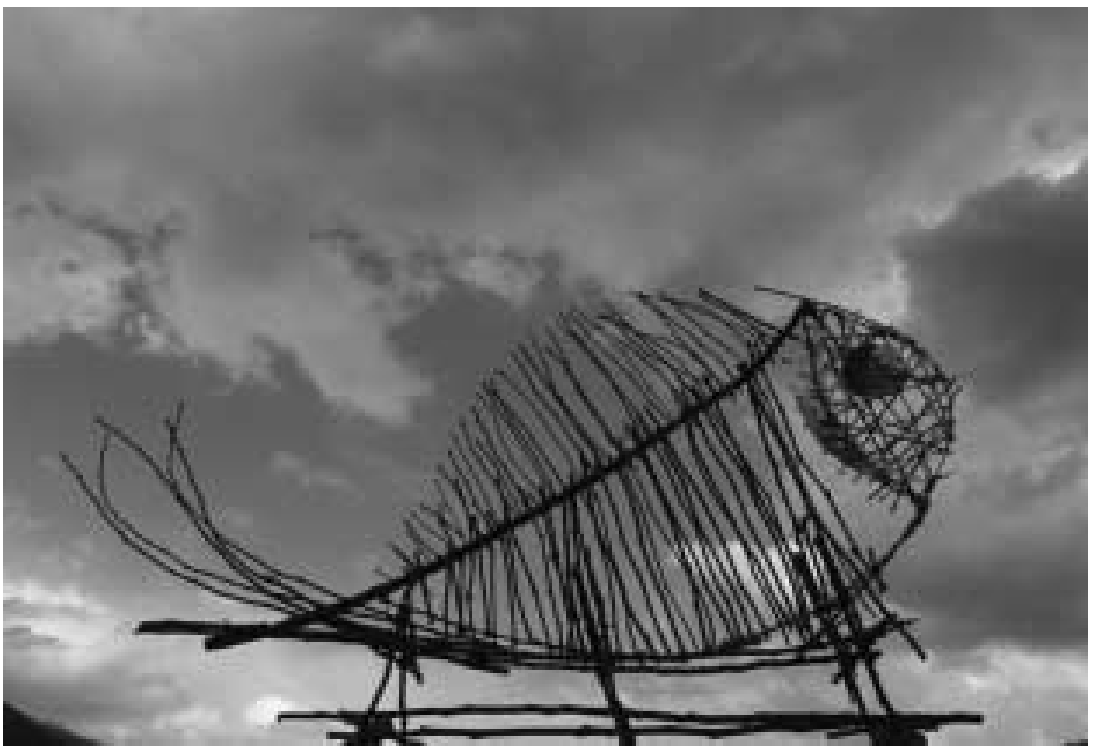

A series of 'fossil' sculptures composed of interlaced branches and sheet-metal, positioned in the meadow by lake Capriati al Volturno, culminating with The Fish, $15 \mathrm{~m} \times 5 \mathrm{~m}$

'hiss of history', the project seeks to elaborate new prospects for the interpretation of local experiences and their worldly connections. ${ }^{4}$ The project will deploy experimental communicative techniques that integrate more traditional communication with the new media, producing documentary, artistic and cultural transpositions of the problematics that connote the territory. Interviews, filmed conversations, written testimonies, photos and physical memorabilia will be integrated with diverse analyses (geographical, historical, anthropological, sociological, etc) in the elaboration of a hypertextual database - Fluid Archive for Mobile Landscapes - that will contribute to a critical perception of both the past and the present which is accessible from any computer terminal on the planet. The principal characteristic of this 'fluid archive' is that it is readable from multiple points of view, offering diverse trajectories through the archive. As an open and stratified series of 'maps', composed of a diversity of elements and languages (geographical, linguistic, social, economical, oral, photographic, musical...), it permits a multiple and open-ended composition of the locality, potentially producing a shifting series of interacting interpretations.

Here, suspended:

... in a worldly network, the dense immediacy of locality and the powerful resonance of a planetary grammar are compounded in an uneven, even unstable, certainly inconclusive, mix. What is produced by this particular space is a critical locality that puts language and thought into movement, sets them in train, propels them on a journey that is 'improper' with regard to any fixed sense of abode, authority and meaning... Here place provides not an idle excuse for theoretical departures and homecomings, but rather, in researching and receiving its overlapping narratives and shifting grounds, the glimpse of a delicate geo-graphy, hesitant, incomplete, destined for decay and subsequent reworkings. In this palimpsest of

See the special issue of Southerly on Paul Carter's work. 'Shared Space Brokered Time: Paul Carter', Southerly, 66:2, 2006. 
language, lives and time, the land, its rugged materiality insists. Its insistence, however, is not that of a perpetual truth but rather one of a temporal frame whose confines and borders set limits that simultaneously nurture the potential of transit. ${ }^{5}$

The activities of Urban Node will be physically housed in a restored building in Gallo Matese, which will provide the space for installations, art shows and video. These will provide the continuing elaboration of the project in an interactive space where the public will be invited to visit the 'Fluid Archive' and contribute their personal testimony. The same structure will also host the organisation of workshops, seminars and conferences, and function as a general information and educational

5 Iain Chambers, 'The Stones in Language', Southerly, $66: 2,2006$, p 60 centre, presenting the eventual documentary platform for a 'Laboratory of Memory' with which to revisit and rethink the histories of the region.

All images copyright PaeseSaggio-Azione Matese, used with permission. 